\title{
Online Instructional Activities for Creative Internet Use of Tertiary Students in Thailand
}

\author{
Wichian Sanmee ${ }^{1}$, Niraj Ruangsan ${ }^{2}$, Prapas Kaewketpong ${ }^{3}$ \\ ${ }^{1,3}$ Faculty of Humanities and Social Sciences, Khon Kaen \\ ${ }^{2}$ Faculty of Education, Mahachulalongkornrajavidyalaya University, Khon Kaen Campus, \\ 1pruan9301@uni.sydney.edu.au, ${ }^{2}$ niraj.rua@mcu.au.th
}

\begin{abstract}
The research aims to study the development of the online instructional activities) for creative internet use of the tertiary students (OIA) in Mahachulalongkornrajavidyalaya University, Khon Kaen Campus (MCUKK), Thailand. The objective of this study therefore is to examine the OIA which researchers have built to use with 30 undergraduate students, selected by a Cluster Sampling in the Faculty of Education. The data collection of this study was conducted by means of both quantitative and qualitative research instruments. The research results are as follows: 1) the OIA consists of the following procedures: (1) planning and orientating the learning activities, (2) motivating to use the internet with creativity, (3) fostering students to create leaning purposes and self-evaluation, (4) presenting individual methods of internet use, (5) presenting the ways to use the internet with creativity, (6) fostering Inquiry-Based Learning, (7) presenting given tasks from selected situations, (8) evaluating by using a sociometry technique and (9) summarizing the aspects of the internet use. Also, the finding reveals the students were very satisfied with the OIA and the positive behaviors of the learners in using the internet with creativity
\end{abstract}

Index Terms

Online Instructional Activities, Thailand, Creative Internet Use

Article Received: 10 August 2020, Revised: 25 October 2020, Accepted: 18 November 2020

\section{Introduction}

The National Education Act 1999 sets out the aims and principles of education management in Section 1, Section 6 that the educational management must develop Thai people to be a complete human being in terms of body, mind, intelligence, knowledge and virtue, ethics and culture of living and happy co-existence [1]. Today, the development of technology for education, religion, arts and culture can be seen from the governmental policies focusing on creating wisdom, morality and ethics in the educational development in consistency with the National Strategy (2018-2037) aiming to develop Thai people to be endowed with virtues, knowledge, good physical and mental health to support them to live together happily [2].

For the management of instructional processes at the tertiary education, learners should have a foundation of knowledge and skills that are sufficient to meet with the desirable characteristics set by the Office of the Higher Education Commission. As mentioned in Thailand Qualifications Framework (TQF), there are five standards for learning outcomes: (1) ethical and moral development, knowledge, (2) cognitive skills, (3) interpersonal skills and (4) responsibility, and (5) analytical and communication skills which includes the capacity to use the information technology and communications [3]. The ethical and moral development aims to help students have ethical and responsible habits for their personal and public lives in the ways consistent with high moral standards with ability to resolve conflicts [3].

In the era when the information technology is developing and changing rapidly, as a result, the communication becomes more convenient and more efficient than in the past. The continuous development of computer system is seen in all kinds of business sectors and now it is more important and the technology becomes a necessary part in life of human beings. Due to the speedy technological change, it leads human beings to adapt themselves for the betterment of their quality of life. The education with the technological advanced supports is an important process that helps humans in every generation adapt and develop themselves to meet the needs in the middle of such change. The education therefore must be constantly adjusted and improved accordingly based on the technological change. In 2019, the Electronic Transactions Development Agency has conducted a survey of the Internet use of Thai people and reported that Thai people used the Internet approximately 10 hours and 5 minutes a day, detailed as using at work for 9 hours and 48 minutes and using in the day-off about 10 hours and 54 minutes. Interestingly, Thai people used the Internet with the e-Commerce value of 3,150,232.96 million Baht or 3.15 Trillion Baht while the percentage of the Internet use increased about $14.04 \%$ [4]. Based in the survey, the Internet was partly used to create a new community as it is an important communication tool which can do various online activities such as online education, business and entertainment. Nowadays, more and more people are living in the online society and the social media is used as a communicator to share the user-generated contents, experiences, articles, photos and videos to the others in their networks. This leads the use of the Internet for social networking to be a popular method among Thai youngsters and also there is a high tendency in other generations.

The Internet is a media that plays a huge role in Thai society. For the creative and safe use of the Internet in Thai society, Thailand Hotline has offered a hotline to ensure that the contents on the Internet are appropriate, legal and not harmful to the society [5]. However, this operation is not new in Thailand. Since 2007 (cited in Bangthamai) [6], the 
Ministry of Education has appointed a working group to create a curriculum for enhancing the creative use and safety of the Internet in educational institutions. In other words, this operation was to encourage young people to use the Internet in a creative and safe way in order to prevent the use of inappropriate websites. The goal of this operational project was to adapt the instructional methods of ICT courses from the old format, which solely focused on technical teaching on the ways to use the Internet or to search for information, to a new way of teaching that focuses on critical thinking of the Internet use such as choosing a website that is valuable and useful, and promotes learning. Alternatively, it was the method to teach children to be aware of online threats from virtual persons through the active learning activities. Since then, the educational institutions under the Ministry of Education have applied many instructional techniques to promote the safety and creative use of the Internet. Somehow, it is to change the behaviors in using the Internet of young people. Based on the literature review, one of the techniques applied to meet the set goal above is the participatory learning technique (PLT) as it allows the learners to be alert at all times, resulting in children being cultivated to think and analyze carefully, to build skills in using the Internet, to reduce the online risk-taking with the strong behavioral immunity that arises from the inner of a well-formed mind [6].

Besides PLT, the self-directed learning (SDL) is an alternative instructional process, suitably used in changing the manners in using the Internet. This technique allows the learners to set their own learning methods by diagnosing their learning needs, choosing goals and learning materials, connecting with others, finding resources, supplementing the learning plans, and evaluating their learning with or without help from the others [7]. In some ways, it is called 'self-taught technique' that make people to learn more by themselves or learn better than the person who is the recipient waiting for the teacher to pass on knowledge even if he/she is studying intently. This is due to the self-taught people have their own learning aims, individuality and directions. Also, they are highly motivated and able to live on their own as learning becomes a part of their lives life. [7]. It is said that SDL has no age limit because the learners have the opportunity to make decisions based on their interests and needs. SDL consists of the eight essential elements: opening of learning opportunities, effectiveness, initiative and independent learning, responsibility, love, creativity, having the optimistic future, and ability to use educational and problem-solving skills [6]. These elements can be applied in all kinds of the self-learning processes.

At the tertiary education level, PLT and SDL are applied as the instructional techniques to develop the graduates in Thailand to have abilities to express their opinions, to make decisions, to work together effectively, to be responsible for oneself and society and to seek knowledge on oneself. This includes those who are studying in MCUKK. As a Buddhist university, teaching morality together with developing the lifelong learning skills of the students becomes an important mission of the university. Today, the educational operation supported by the advance of information technology plays a particularly important role in promoting learning the campus. To meet with TQF criteria set by the Office of the Higher Education Commission, that is the desirable characteristics of the graduates in using the technology, the university has to develop the specific instruction for altering the students' manners in using the technology in the creative ways. Therefore, the online instructional activities (OIA) has been created to use with the students in MCUKK in 2019. It seems to be impossible to change all the manners in using the technology, the OIA so aims only to alter the behaviors of the students in using the Internet in supports of PLT and SDL. Based on this operation, this study aims to examine the development of OIA to promote the creative use of the Internet of the students in the campus.

\section{Research Objectives}

The objective of this study is to examine the created OIA in terms of appropriateness of its components based on the students' satisfaction and effectiveness (levels of practice) in altering students' behaviors in using the Internet.

\section{Reserch Methodology}

In order to answer the questions regarding to the appropriateness of its components and effectiveness of OIA as mentioned, the research method and some details should be clarified for the reliability reasons.

\section{Population and Samples:}

The population of this research included 120 students (FirstFifth years) studying in the Bachelor Degree in Teaching Thai Language and Teaching Social Sciences, Faculty of Education, MCUKK. Selected by Cluster Sampling, the samples of this study included 30 students who were willing to join the OIA.

\section{Variables \\ Independent variable: OIA}

Dependent variable: appropriateness of OIA and behavioral change effectiveness of OIA

\section{Research Tools}

In order to carry out the research, the researchers have used to following tools in the operation: (1) The questionnaire (Q1) probing the conditions of learning and guidelines to design the OIA; (2) Focus-Group of five experts in the relevant fields; (3) the OIA; (4) the questionnaire (Q2) probing the attitude (satisfaction) of students with the OIA's components and (5) the evaluation form (F1) of students' behaviors in using the Internet with creativity and (6) interview form (F2).

\section{Research Process}

This research process is divided into 5 phases based on the ADDIE model [8] [9] as follows:

\section{Phase 01: Analysis}

The researchers have studied and analyzed the conditions and guidelines to design OIA through analyzing all relevant 
documents, research as well as the data obtained from response to Q1.

\section{Phase 02: Design}

The researchers have designed OIA focusing on its essential elements such as objectives, structure and content order, learning activities and strategies, evaluation criteria and lesson flowchart.

\section{Phase 03: Development}

The researchers organized Focus Group of five experts in the related fields of study to get advices and suggestions to develop OIA. Then the edited OIA was tried out with a small group of non-samples (10) in other faculties in the campus. Then, the formative evaluation has been conducted. Finally, OIA has been revised and ready to be implemented.

\section{Phase 04: Implement}

OIA for creative internet use has been implemented with 30 samples, selected by Cluster Sampling for one semester (June-October) in 2019.

\section{Phase 05: Evaluation}

After the implement, the evaluation of OIA has been conducted by using Q2, F1 and F2. Finally, all the gathered quantitative data were analyzed by the following statistics: Percentage, Mean, Standard Deviation and t-test (dependent). For the qualitative data were analyzed by the descriptive analysis based on the inductive reasoning method.

\section{Results}

OIA is defined as the instructional activities for the proper use of the Internet or using the Internet in the awareness of its online benefits as well as hidden danger. It is designed to use with the tertiary students at MCUKK in order to promote the creativity use of the Internet according to TQF set by the Office of the Higher Education Commission and to respond the National Strategy mentioned above. In regards to the appropriateness of OIA components, OIA consists of nine important components and each has statistically been rated (Mean and S.D.) as follows: (1) planning and orientating the learning activities $(4.87,0.07)$, (2) motivating to use the Internet with creativity (4.20, 0.38 ), (3) fostering students to create leaning purposes and self-evaluation $(4.60,0.36)$, (4) presenting their individual methods of internet use $(4.42,0.48)$, (5) presenting the ways to use the internet with creativity $(4.74,0.43),(6)$ fostering IBL (inquiry-based learning) $(4.47,0.43)$, (7) presenting given tasks from selected situation $(4.33,0.40)$, (8) evaluating by using a sociometry technique $(4.60,0.40)$ and (9) summarizing the aspects of the internet use $(4.62,0.20)$. The overall mean value of the students' attitude towards OIA was a very high level $(4.54,0.34)$, meaning that the students were very satisfied with OIA components and its appropriateness.
In relations to the evaluation of students' behaviors in using the internet with creativity, the overall measured mean score indicated a moderate level of practice $(3.10,0.42)$. The measurement was divided in five aspects: (1) use of internet that was safe for others $(3.40,0.37)$; (2) self-protection against internet misuse $(3.22,0.44)$; (3) use of the Internet that is beneficial to oneself and others $(3.02,0.28)$; (4) suppression of offenders on the Internet $(2.81,0.41)$; (5) guidelines for constructive use of the Internet $(2.60,0.59)$. The comparative result of the students' learning indicates that the statistical mean value (t-test dependent) of the Internet use with creativity of the students after learning with the OIA was higher than that of pre-learning with the statistical significance level of .01 .

\section{Discussion}

1) OIA was developed based on the psycho-development principle to design of the teaching-learning activity model of Kaemmanee [10], who spoke of guidelines for psychomotor domain. The OIA consists of the nine procedures as mentioned above. All the elements had been designed based on the results of study and analysis of the conditions and guidelines gathered from relevant documents, research and the data obtained from response to Q1 in line with the Creative Internet Guidelines to use the Internet to develop students in terms of teaching and learning [6]. Of all the components, the majority of the sample were satisfied with the first component most: (1) planning and orientating the learning activities. The reason for this is that they want to know the nature of OIA and the necessary and importance to comply the stages of OIA. Based on the interview, most of students were satisfied with PLT as it allows them to build skills in using the Internet with creativity based on their interests and interactions with the teachers and classmates. More importantly, this technique allows the students to choose to get involved and connected with the classmates they like through their commonly used social network applications. This is consistent with the research results of Patreeya 2019 [11] mentioning the nursing students used the Internet to connect with the others through Facebook, Instagram and Twitter. In relations to the additional content, the researcher has added the moral teaching while introducing and operating OIA in each procedure. All the moral doctrines were taught under the main principle of Buddhism called 'the Three Admonitions or Exhortation of the Buddha'. And, they are: not to do any evil, to cultivate good and to purify the mind [12]. However, as the samples are the students in the Buddhist University, teaching the morality does not seem to gain their interests much and they have already got used to the Buddhist doctrines. To solve this issue, the case studies on the online threats and advantages of using the Internet for success have been exemplified for the students, together with teaching morals. In relations to SDL, it provided a huge advantage to OIA as it raises the self-responsibility to the students in line with the Hiemstra's principle [13] mentioning that SDL is selflearning with responsibility as a basis. SDL is the process in which an individual takes the initiative to diagnose a learning need and studies planning, requires learning resources and learning evaluation. In other words, the learner is the one who studies and searches for and creates 
knowledge. And, they have to be responsible for performing tasks. It may or may not rely on help from others. On the other hands, based on the interview, some students got straggles in creating their own ways of learning. Some confessed that often they cannot control the feelings for example sometimes they visited pornography or gambling websites. The solution for this, the students are advised to be aware of the advantages and disadvantages of their actions and try to avoid misconducts and some were given advices and guidelines.

2) The evaluation of creative internet use behaviors of the students in 5 areas has been conducted as follows: (1) Use of internet that is safe for others: (1.1) know and understand of the Computer Act 2007; (1.2) good attitudes towards the Internet use; (1.3) plan before using the Internet; (1.4) check data validation before communicating with the Internet; (2) self-protection against internet misuse: (2.1) select learning content; (2.2) show the idea of using the Internet creatively; (2.3) explain how to use information obtained from the Internet; (2.4) have skills in solving problems in studying; (3) use of the Internet that is beneficial to oneself and others, detailed as follows: (3.1) share knowledge with others; (3.2) have interpersonal relationships; (3.3) honor the contributions of others; (3.4) participate in learning; (4) suppress offenders on the Internet: (4.1) debate against websites that are not beneficial to society; (4.2) promote action against offenders on the Internet; (4.3) inform offenders to district officials; $(4.4)$ be a role model for others; (5) guidelines for constructive use of the Internet: (5.1) establish the guidelines for creative use of the Internet, (5.2) produce media that promotes creative use of the Internet, (5.3) cite the others' works, (5.4) disseminate the information to promote the creative use of the internet through various media. Based on the interview, most students mentioned that some evaluation items in each aspect are too difficult to follow. For example, the students found it hard to know and understand of the Computer Act 2007 in details. Although the overall mean score of the behaviors of the students is in the moderate level of the practice, the evaluation result of the students' learning indicates the positive behavioral changes of the Internet use the students after joining OIA. This is to be concluded that OIA created has a positive effect on the behavior of the studied students.

\section{Suggestions}

1) The OIA for the internet use with creativity should be used to study the different groups of samples such as those studying in other universities.

2) To gain better results of the OIA, it should be used to study the larger size of the population within the university.

3) The university or stakeholders should use the results of this study to regulate policies of the Internet use with creativity of the students.

\section{References}

[1] Office of Policy and Educational Plan Religion and Culture Office of the
Permanent Secretary Ministry of Education. National Education Act of B.E. 2542. 1999 [cited 2020 13/01]; Available from: www.nso.go.th.

[2] Office of the National Economic and Socail Development Council. National Strategy. 2020 [cited 2020 22/10/2020]; Available from: http://nscr.nesdb.go.th/wpcontent/uploads/2019/10/NationalStrategy-Eng-Final-25-OCT-2019.pdf.

[3] Office of Higher Education Commission. National Qualifications Framework for Higher Education in Thailand: Implementtation Handbook. 2006 [cited 2021 13/01]; Available from: http://www.mua.go.th/users/tqfhed/news/FilesNews/FilesNews8/NQFHEd.pdf.

[4] Electronic Transactions Development Agency, ETDA Annual Report 2019. 2019: Bangkok.

[5] Thai Hotline. History. 2020 [cited 2020 13/01]; Available from: https://thaihotline.org/en/history/.

[6] Bangthamai, E., The Development of Learning and Teaching Activities through Online Social Networking to Promote Creative Internet Using for Students in Tertiary Level. Silapakorn Universiry Journal, 2017. 37(1): p. 93-118.

[7] Phiromnok, N., An Instructional Model Development in Computer Graphic Course Focusing on Self-Directed Learning Process of Information Technology Undergraduate Students, Suan Dusit University. Vocational Education Innovation and Research Journal, 2019. 3(1): p. 51-57.

[8] Yuangngoen, W., Blended Learning Management of WordPress Website Development Skill for Communication Design Undergraduates Using the ADDIE Model. International Journal of Inductrial Education and Technology, 2020. 1(1): p. 50-58.

[9] Tawatchai Sahapong, Effect of Developing the Multimedia (ADDIE Model) to 
Enhance the Tradition and Culture in the Subject of Development of Electronics Media for Learning. Journal of Technology Management Rajabhat Maha Sarakham University, 2020. 7(2): p. 7-14.

[10] Kaemmanee, T., The Development of Morals, Ethics and Values: From Theory to Practice, ed. s. Edition. 2003, Bangkok: Sermsin Prepress System.

[11] Phatreeya Damrongsat, W.S., Factors Influencing creative internet use of nursing students. Journal of Health Research and Innovation, 2019. 2(1): p. 220-228.

[12] Payutto, P.A., Dictionary of Buddhism. 2002, Sahadhammika Press: Bangkok.

[13] Hiemstra, R., Self-Directed Learning, in The International Encyclopedia of Education, T.N.P. T. Husen, Editor. 1994, Pergamon Press: Oxford. 